\title{
Amygdalar CB2 cannabinoid receptor mediates fear extinction deficits promoted by orexin-A/hypocretin-1
}

\author{
Marc Ten-Blanco ${ }^{1}$, África Flores ${ }^{2}$, Inmaculada Pereda-Pérez ${ }^{1}$, Fabiana Piscitelli ${ }^{3}$, Cristina $^{2}$ \\ Izquierdo-Luengo $^{1}$, Luigia Cristino ${ }^{3}$, Julián Romero ${ }^{1}$, Cecilia Hillard ${ }^{4}$, Rafael Maldonado ${ }^{2}$, \\ Vincenzo Di Marzo ${ }^{3}$, and Fernando Berrendero ${ }^{1}$ \\ ${ }^{1}$ Francisco de Vitoria University \\ ${ }^{2}$ Pompeu Fabra University \\ ${ }^{3}$ Institute of Biomolecular Chemistry National Research Council \\ ${ }^{4}$ Medical College of Wisconsin
}

December 9, 2021

\begin{abstract}
Background and purpose: Anxiety is often characterized by an inability to extinguish learned fear responses. Orexins/hypocretins are involved in the modulation of aversive memories, and dysregulation of this system may contribute to the aetiology of anxiety disorders characterized by pathological fear. The mechanisms by which orexins regulate fear remain unknown. Experimental approach: We investigated the role of the endogenous cannabinoid system in the impaired fear extinction induced by orexin-A (OXA) in male mice. Behavioural pharmacology, neurochemical, molecular and genetic approaches were used. Key results: The selective inhibitor of 2-arachidonoylglycerol (2-AG) biosynthesis O7460 abolished the fear extinction deficits induced by OXA. Accordingly, increased 2-AG levels were observed in the amygdala and hippocampus of mice treated with OXA that do not extinguish fear, suggesting that high levels of this endocannabinoid are related to poor extinction. Impairment of fear extinction induced by OXA was associated with increased expression of CB2 cannabinoid receptor (CB2R) in microglial cells of the basolateral amygdala. Consistently, the intra-amygdala infusion of the CB2R antagonist AM630 completely blocked the impaired extinction promoted by OXA. Microglial and CB2R expression depletion in the amygdala with PLX5622 chow also prevented these extinction deficits. Conclusions and implications: We reveal that overactivation of the orexin system leads to impaired fear extinction through 2-AG and amygdalar CB2R. This novel mechanism may pave the way towards novel potential approaches to treat diseases associated with inappropriate retention of fear, such as post-traumatic stress disorder, panic anxiety and phobias.
\end{abstract}

\section{Hosted file}

manuscript.docx available at https: //authorea.com/users/450495/articles/548779-amygdalar-cb2cannabinoid-receptor-mediates-fear-extinction-deficits-promoted-by-orexin-a-hypocretin-1 
Figure 1
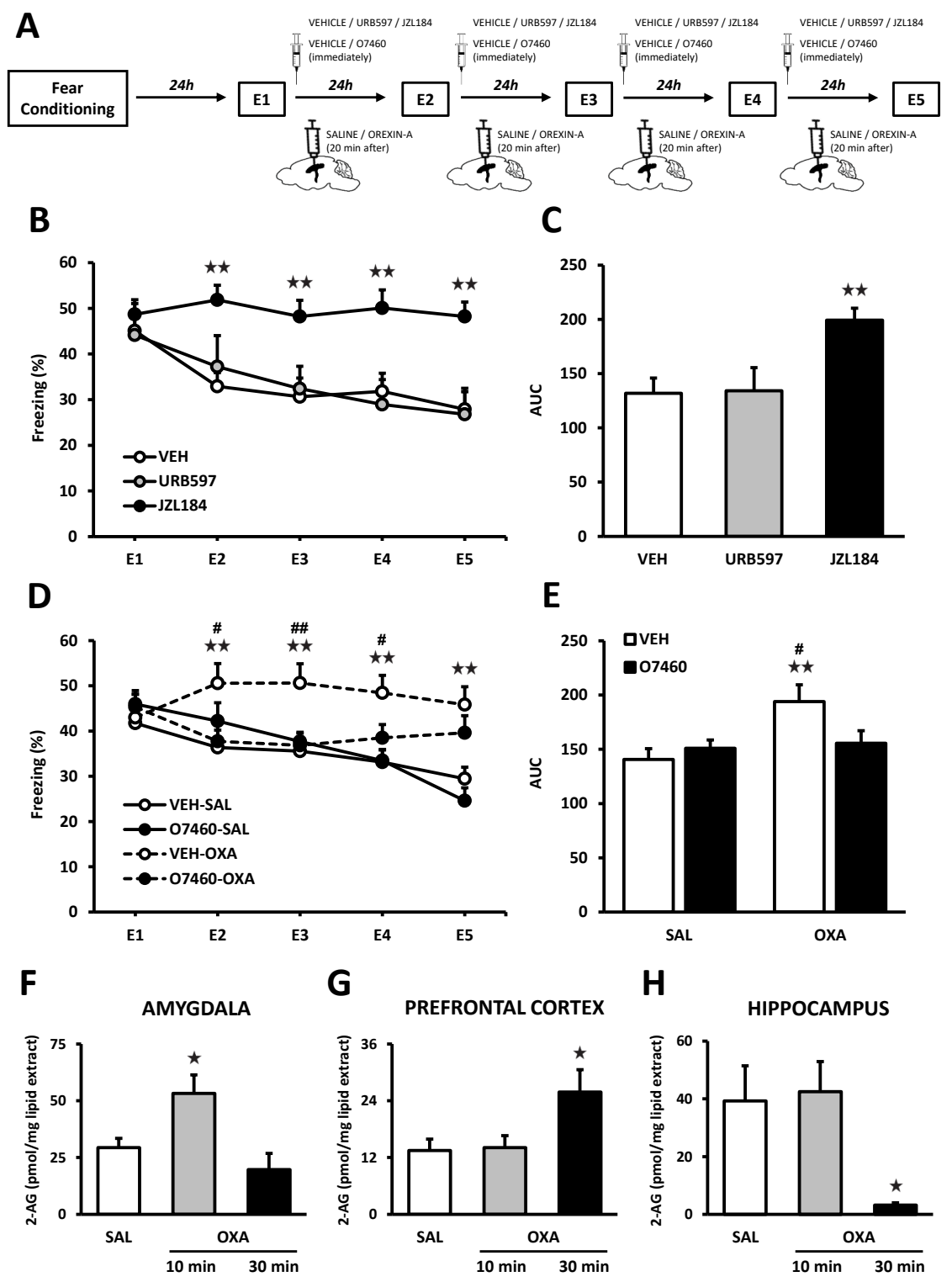
Figure 2

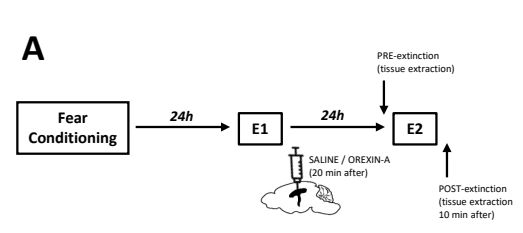

C

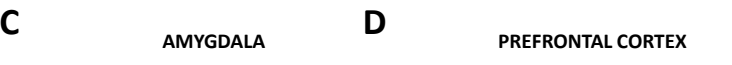

B

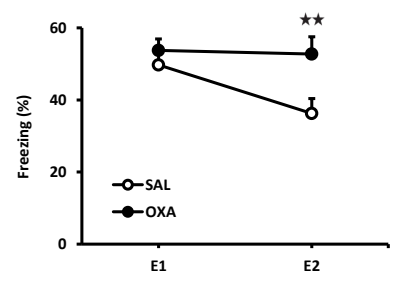

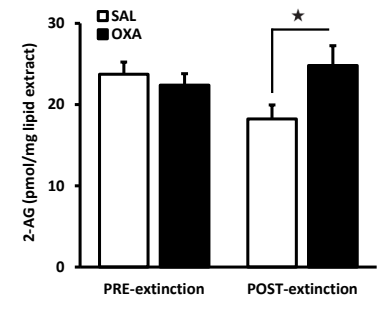

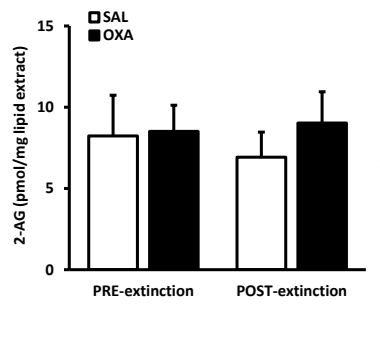

E HIPPOCAMPUS

F

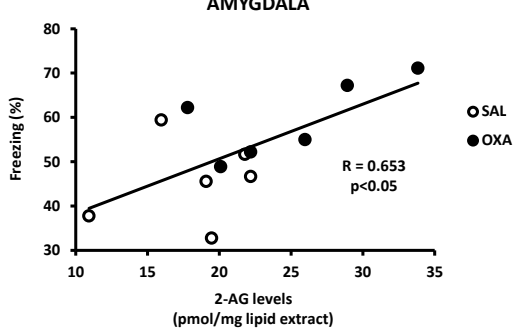




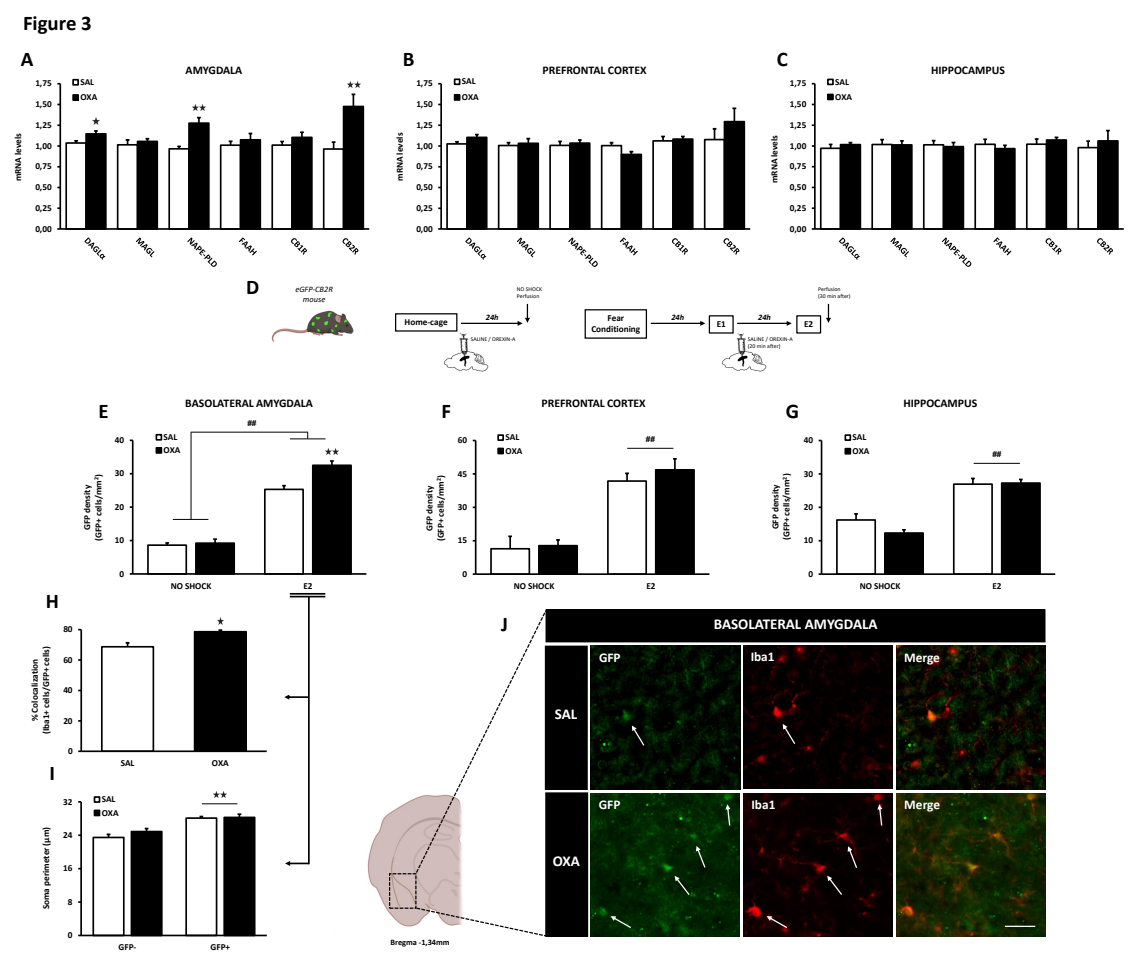


Figure 4
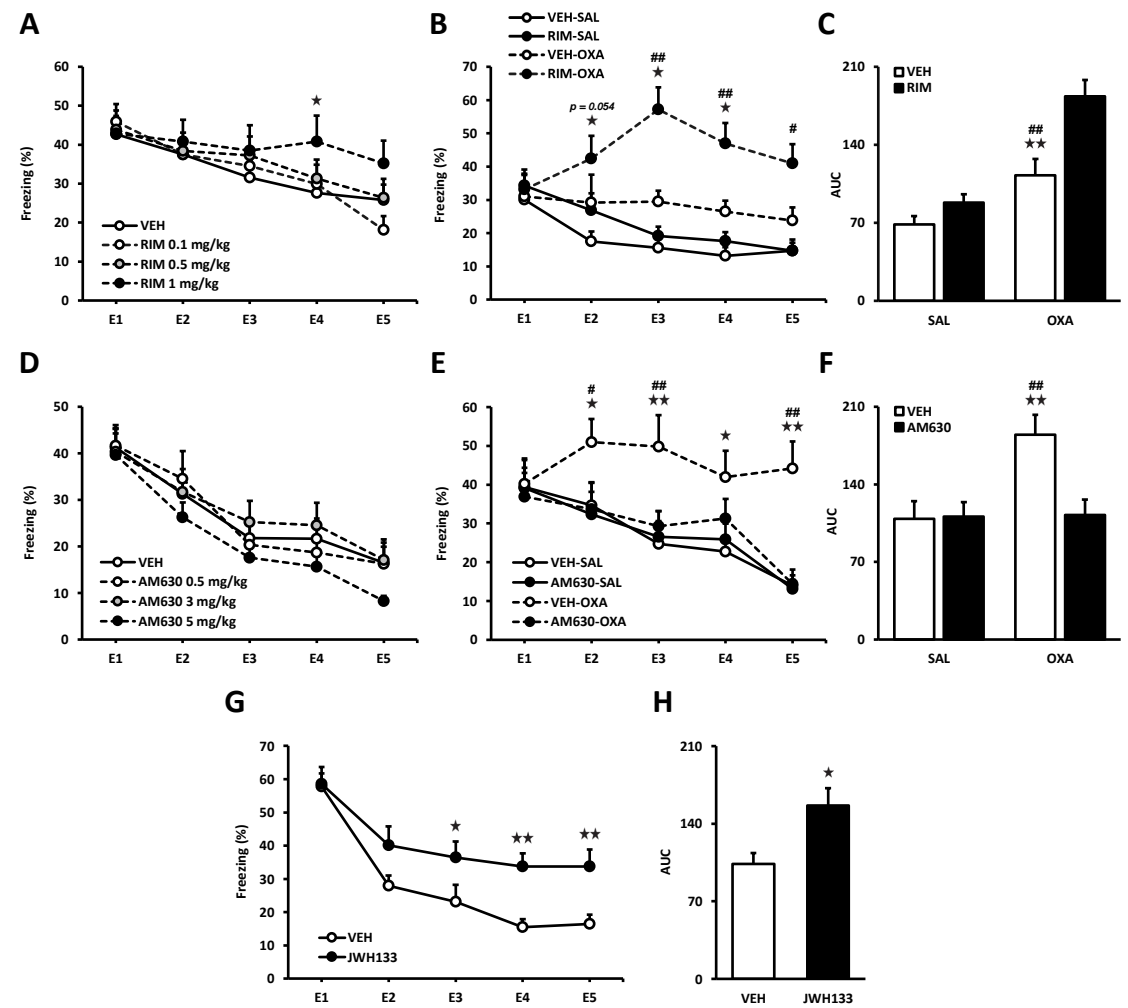

Figure 5
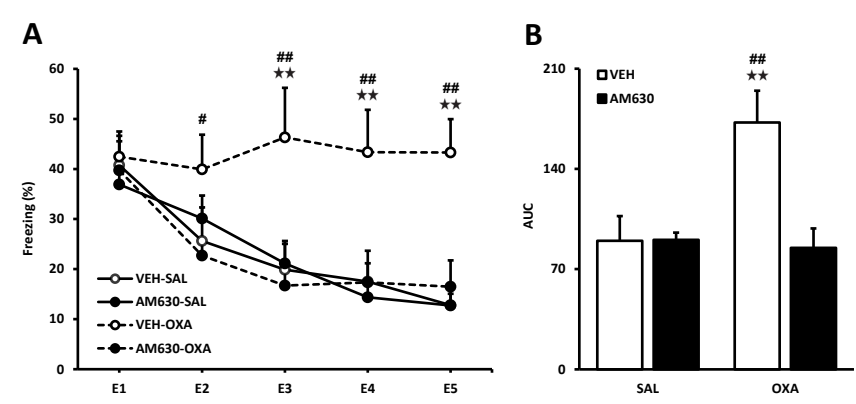

C

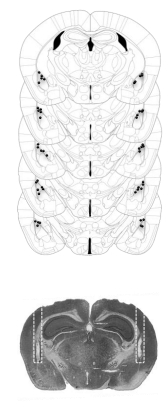


Figure 6
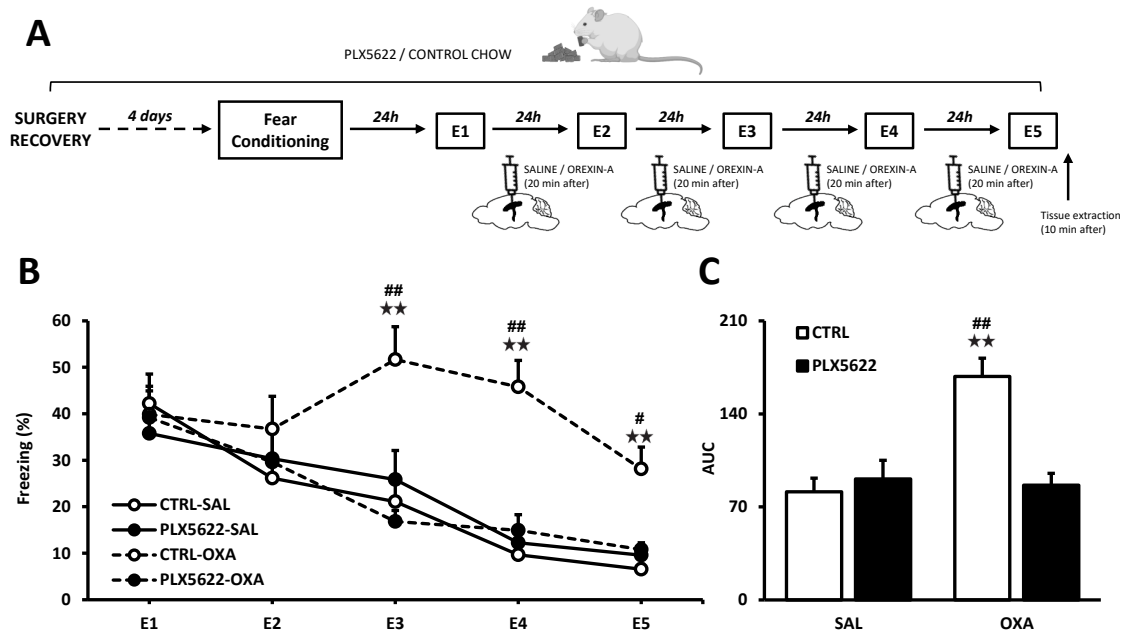

C
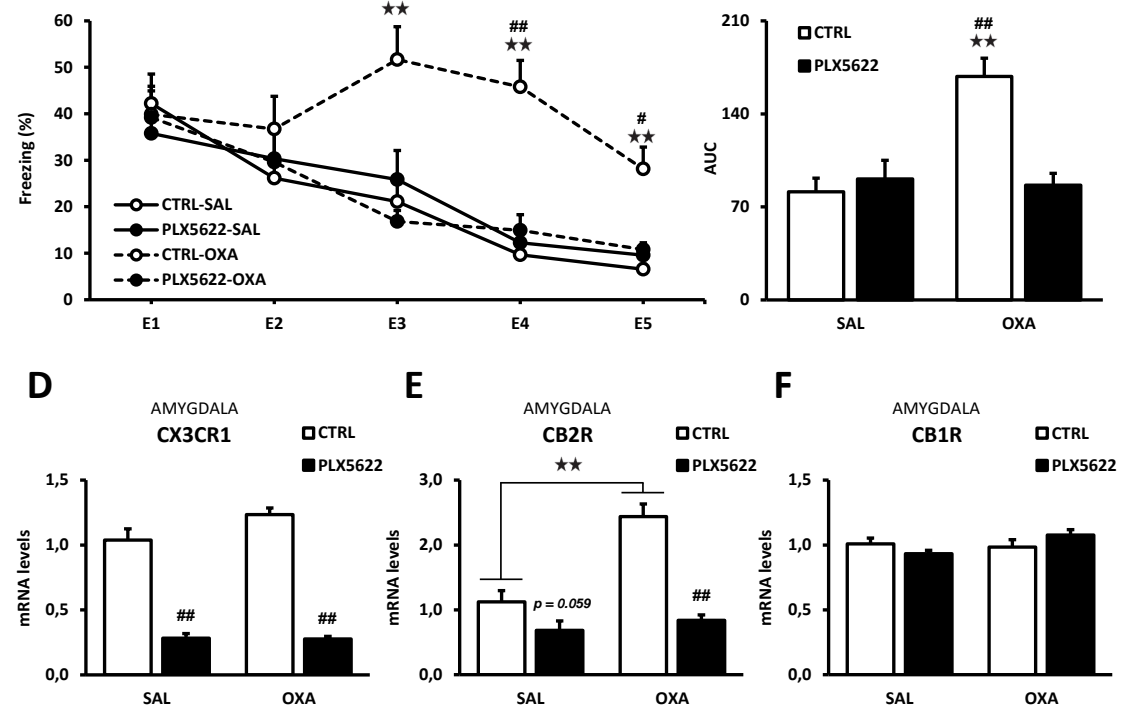